\title{
A Report of Dealing with Sadness Using Hypnosis Technology Jing $\mathrm{Wu}$ \\ Xi'an Medical University, Xi'an, China \\ 46441194@qq.com
}

Keywords: College students; Sadness; Report

\begin{abstract}
Objective: Through the consultation of a female college student, psychological counselor effectively help the bereaved girl out of the shadows, and improve the quality of life and learning efficiency. Methods: According to the generalized analysis, the problem of the client was post-traumatic stress disorder, psychological counselor mainly used grief therapy and hypnosis technology to help the client. Results: The girl accepted the fact that her mother died, she was able to get rid of the depression, and to face the future with a positive attitude. Conclusion: Hypnosis technology can help college students who from special family spend their hard times, the timely and effective support of the psychological counseling agencies plays a vital role in the emotional recovery of college students.
\end{abstract}

\section{Introduction}

Sadness is thought to be an emotional response to external events such as separation, loss and failure. Due to factors such as individual evaluation standard, the personality traits of different, the same event or situation can cause the strength of the grief, sorrow, sorrow for the duration of will also be different [1]. Levenson, the core of the emotional theory, grief was initially triggered by prototype events, but in the case, when the prototype event meet the lose (loss) of condition, the result will be a sad mood [2]. The emotional process theory (Gross) suggests that the sad experience is the result of the emotional cues that are rated [3]. Xiaoming Jia and [4] say that grief is a very sad experience and a process of repair after death and loss.

Death is not the misfortune of the dead, but the misfortune of the living. Therefore, the grief counseling of the living can effectively unsettle the sadness of the living and avoid the health problems.

Xiajiang Zheng and others believe that "grief counseling is a psychological rehabilitation process for the grieving person" [5].

In the theory of grief counseling, Worden believes that the ultimate goal of grief counseling is to assist the living in completing the unfinished business and saying goodbye to the deceased. Specific goals for the mourning mission include: (1) increasing the sense of reality of loss; (2) to assist the parties in dealing with expressed or latent emotions; (3) assisting the parties in overcoming the obstacles in the process of adaptation; (4) encourage the parties to bid farewell to the deceased. In a healthy way, you can refocus your emotions in a new relationship and continue to live effectively in [6].

Hypnosis is using the suggested method to make patients into a special state of consciousness, control in patients with psychosomatic activities, so as to lift and psychosomatic problems for the treatment of patients with psychological therapy [7]. According to the relevant theory, the consultant has conducted effective psychological intervention for a female college student and has achieved good results.

\section{Case and Method}

Case Basics. Visitor A, female, 22, junior, from the countryside. Mother died of illness a year ago. Family member: have two younger sister a younger brother, younger sister already married, elder sister and younger brother all go out to work, economic poverty. No genetic history of the family, no history of mental illness. 
My mother died on the first afternoon of my first day of winter vacation. The visitor was very sad about her mother's death, and when she spoke of her mother's death, she was crying and describing her feelings of guilt. I think I hated my mother because of the bad and silly things left by her cerebral thrombosis before her mother died. However, since her mother died, she was always guilty of not treating her mother well. Now the heart is in anguish. Keep back to the previous life, hope that my mother still alive, sometimes when I think of mom will shed tears, hope I can put things right in life now, but always feel do not good, feel every day is not happy, sad.

Evaluation of Visitors. The visitor suffered a great deal of trauma after his death. Visitors suppress their emotions and live in a deep sense of self-blame and guilt, which leads to sleep and reduced learning efficiency. But the visitors the process of cognition, emotion and meaning is unified, for their own psychological problems have self-knowledge, and take the initiative to seek treatment, no logic of chaos, the abnormal sense perception, no psychiatric symptoms such as hallucinations, delusions, so can eliminate mental illness.

Visitors, although there are also depressed mood, this is because the real event, and the degree of light, no suicide, not seriously affect its social function and logical thinking, so it can eliminate depressive neurosis. Visitors also have anxiety symptom, but also did not seriously affect the social function and logical thinking, psychological conflict not deformation, no generalization, so it can eliminate anxiety neurosis.

According to visitor's emotional reaction is relatively strong, content of generalization, have very good self-knowledge and checking, combined with the basic information of the visitors, according to the above-mentioned evaluation, consider the visitor belongs to post-traumatic stress disorder.

Consultation Process. According to the problem of visitors, mainly USES the humanism concept in the process of consultation, combines the technique of hypnosis therapy, the patient treated correctly "lost", out of the shadow of her mother's death.

Consulting the first stage (1-2) : to diagnose and evaluate the visitor and establish a relationship.

Consultant first introduce the basic situation of psychological counseling to visitors, consultants and visitors the rights and obligations of both sides, the emphasis on confidentiality of psychological counseling, to give visitors a safe space. Encourage visitors to talk about their current psychological and physical condition. Visitor's basic information collection, consultant, through careful listening and watching, understands the growing experience of visitors: visitors eldest at home, parents are migrant workers for many years, the visitor has lived with grandparents. When the visitor was 15 years old, his parents came back from work, and a year later, the mother had a cerebral thrombosis, the hands and feet were inflexible, and the person became a bit dull. Since her mother was ill, the visitor has been at odds with her mother, sometimes doing things that are disrespectful to her mother. So, after her mother died, she felt very guilty.

This phase through mastery of basic information, to evaluate the visitors, determine the visitors desired change, determine the main problems and solutions of visitors, to introduce the basic knowledge of hypnosis, visitor to eliminate the doubts of the visitors. Through empathy, the consultant creates a psychological resonance for visitors and feels the real understanding and care from the consultant. Establish a good relationship.

Consulting the second stage ( $3 \sim 4$ times) : this phase in the relationship between consultants and visitors a good, on the basis of using hypnosis technique was effective intervention to visitors.

This stage is the key to the treatment, except to further strengthen the therapeutic relationship, to understand the visitor's problems, and to make hypnotic interventions to visitors.

The third consultation, the hypnotic guide phase: let the visitor sit comfortably, first take a deep breath, relax the two shoulders, and feel the smoothness of the breath... Guide the visitor to see the fruit in front of you, as well as its color, shape and size...

By using the guidance language, the visitor returns to his home. In looking around the room a week later, the visitors to see his mother in the room, see mother visitors began to cry bitterly, visitors describe the looked at her mother's love, smile did not blame her. The therapist guides the visitor to the mother and hugs her mother. Themselves inside of the heart want to say to mom and said before expressing it said to mother "I love you, mom. Mom, I'm sorry, I should not be so for 
you before..." Repeat it over and over again, dealing with the inner remorse and guilt. Finally, guide the visitor to say goodbye to her mother and express her words to her mother. Through hypnosis to help the visitor to say goodbye to his mother, the reality has not been done.

The fourth consultation: guiding the visitor to the top of the sky and seeing a cloud in the sky in the distance. As the clouds got closer, I found my mother standing on the cloud. Guide visitors communicate with mother is the heart and heart communication, tell visitors can open up, give mother told mom, want to say or don't want to say, now want to say words out, mother can understand visitors express everything. At this time, my mother also told the visitors she has her way, visitors have visitors life, guide visitors told mom respect the choice of the mother, and mother said goodbye to each other and blessing. Finally, the clouds that my mother stepped on were slowly disappearing into the sky...

By further hypnosis intervention to help visitors to relief grief, express thoughts of the visitors, the visitors catharsis mood, allowing visitors to inner peace.

The third stage of consultation $(5 \sim 6)$ : to end the consolidation phase, strengthen the positive emotions of the visitors, consolidate the existing benefits, and finish the preparation work.

Fifth consultation, guide the visitors face their own sadness, face up to the fact that they have gone, I wrote a letter to mom let visitors to express gratefulness for women and deep thoughts, feel mother's love will bring a steady stream of mental energy, mama and empathy to their expectation, lighten the visitor's guilt, finally let visitors will letter to mom back, find a place they see fit and safe to burn. In this way, do spiritual conversations and goodbyes with your mother. Let the visitor acknowledge the fact that her mother has passed away from cognition and emotion, and enhance the sense of reality of mother's death.

In the sixth consultation, the consultant reacquainted himself with his family and friends and reshaped the social support system of his visitors. , by giving visitors into hope, let its experience, say goodbye to the pain, to guide visitors pay attention to personal growth, with a positive mental attitude to face the life, the end of the consultation.

\section{Results}

This case consulting 6 times, in addition to the first and second consultation between the two weeks, the remaining four times for 1 week, 50 minutes every time, because is the school counseling, consulting does not charge any fee.

Consultation over three months later, the visitors through the email form to the consultant feedback, a lot of emotional stability after the treatment, think of mom or see pictures of mom is not as sad as he used to be. At the same time, I can focus on the present life and be able to actively face the learning life. It is satisfactory to the present state, and basically meets the expectation effect of the consultation.

\section{Discussion}

In traditional Chinese culture, people are used to suppressing their emotions, such as "a man's tears and not a light bullet" and "the ability to turn grief into strength". Think that crying is a sign of cowardice, and the individual needs to hide his sadness well. In fact, in the face of loss, the individual needs time to deal with his feelings. If it is not handled well, it may further damage individual growth and development.

First, a proper release is an effective way to help visitors get out of mourning. In consulting, the consultant will be visitors repressed sad emotion and thoughts bear out for relatives, can effectively reduce the number of visitors to depression and anxiety, help visitors out of the haze, as soon as possible a happy life.

Secondly, the popularization of psychological knowledge is very important. Because the prevalence of psychological literacy is still low, many traumatized people don't have enough awareness to find resources to help. Because the visitor is in high school, study the psychology course, the psychology counselling acceptance is higher. The younger siblings of the visitors, by 
contrast, have the same trauma but adjust themselves for a variety of reasons. Therefore, it is very important to popularize the knowledge of psychology, such as mass media.

Finally, because the psychological counselling and treatment is a very professional job, not only need long-term regular school education, also need to continue education and clinical supervision, otherwise it may cause serious harm to the service object. There may also be an absence of full training in the practice of consulting outpatient services in the formal medical establishment. It is suggested that the psychological consultation organization should train the professionals regularly, improve the technical level of the counselors, and better serve the public.

\section{Acknowledgements}

The education teaching reform research program of Xi' an Medical University:The innovation education model researchof combine the course of Medical psychology in local medical schoolsand the mental health education of college students(item number: 2016JG-27)

\section{References}

[1] C.H.Jiang,L.Zhao.Research on sadness and its response [J]. Journal of capital normal university (social science). 2006, (2) : 108-114.

[2] Levenson R W. Autonomic specificity and emotion[A]. In R J Davidson, K R Scherer, H H Goldsmith(Eds.). Handbook of Affective Science[C]. New York: Oxford University Press, 2003.

[3] Gross J J. Emotion regulation: affective, cognitive, and social consequences [J]. Psychophysiology, 2002,(39): 281-291

[4] X.M.Jia.From folk memorial to psychoanalysis - the process of loss of grief [J]. Journal of Chinese mental health, 2005, 19 (8) : 569-571.

[5] X.J.Zheng, Z.C.Niu.Interpretation of life and death [M]. Beijing: social science literature press, 2005 .

[6] Worden,J.W., Grief counseling and grief therapy. London: Rourledge.1991.

[7] S.Q.Yao,Y.C.Yang etc. Medical psychology [M]. Beijing: people's health press, 2013.228.

[8] X.D.Zhao,Z.Cong,D.L.Zhang.About professional psychological counselling and treatment problems and Suggestions in the development of [J]. Chinese journal of mental health, 2005, 12 (3) : 221-225. 